\title{
Occult connective tissue diseases mimicking idiopathic interstitial pneumonias
}

\author{
G.E. Tzelepis*,\#, S.P. Toya*,\# and H.M. Moutsopoulos*,\#
}

ABSTRACT: In patients with interstitial lung disease (ILD), the diagnosis of idiopathic interstitial pneumonia is usually made after excluding, among other conditions, connective tissue diseases (CTDs). Although in most patients with a CTD and respiratory symptoms, the systemic nature of the disease is obvious, the ILD-related manifestations in CTDs may often dominate the clinical picture or precede systemic findings and thus mimic idiopathic interstitial pneumonia.

With the exception of systemic lupus erythematosus, all CTDs may imitate chronic idiopathic interstitial pneumonias. In this setting, clues to an underlying CTD may be entirely absent or include subtle findings from various systems, including skin, vascular and musculoskeletal system or internal organs. Since nonspecific interstitial pneumonia is a relatively frequent histological pattern in CTDs, biopsy reports of nonspecific interstitial pneumonia should also prompt a search for an underlying CTD.

Ultimately, diagnosis of a CTD requires confirmation with immunological testing; interpretation of the various laboratory tests should always be carried out in conjunction with clinical findings.

The present article reviews specific clinical aspects of connective tissue disease-related interstitial lung disease that may help differentiate it from idiopathic interstitial pneumonia, especially when interstitial lung disease is the predominant or sole manifestation of an occult connective tissue disease.

KEYWORDS: Connective tissue-related, idiopathic pulmonary fibrosis, interstitial lung diseases

$\mathbf{T}$ he term idiopathic interstitial pneumonias (IIPs) refers to a heterogeneous group of acute, subacute or chronic interstitial lung diseases (ILDs) characterised by different combinations of inflammation and fibrosis, as well as by a restrictive pulmonary defect and abnormal gas exchange [1,2]. The most common form of IIP is idiopathic pulmonary fibrosis (IPF) [3-5]. The IIPs account for a substantial portion, $\sim 25-30 \%$, of all ILDs [6, 7]; the remaining ILDs include various occupational, drug-induced and connective tissue diseases (CTDs), as well as disorders of unknown cause [1].

In the absence of clinical or laboratory tests specific for IIPs, their diagnosis is critically dependent upon the exclusion of certain drug toxicities, environmental exposures and CTDs [1, 2]. Unlike external causative factors that may be suspected from a pertinent exposure or drug history, an occult CTD may occasionally confuse the diagnostic process because the CTD-related respiratory symptomatology may not always be accompanied by systemic manifestations and thus mimic IIP $[7,8]$.

The present article focuses on specific CTDs that may present solely or predominantly with chronic ILD-related symptoms. Since such patients are often seen by a non-rheumatologist, the present article is intended to help the clinician suspect an underlying CTD as the cause of ILD in the occasional patient with respiratory symptoms and no apparent systemic involvement. It does not deal with the wide spectrum of respiratory manifestations related to CTD, as in-depth reviews devoted to this topic can be found elsewhere [9-11].

\section{CTD MIMICKING IIP: PREVALENCE AND SIGNIFICANCE OF EARLY DIAGNOSIS}

The most frequent types of ILD encountered in patients with CTD are nonspecific interstitial pneumonia (NSIP), usual interstitial pneumonia (UIP), acute interstitial pneumonia, cryptogenic organising pneumonia (COP) and lymphocytic interstitial pneumonia (LIP; table 1) [9, 12-16]. By and large, these entities exhibit similar radiological and histological characteristics to their idiopathic counterparts and are thus considered indistinguishable [15, 17-19]. Despite similarities in histological and radiological profiles, there are significant differences in survival between the two groups. Patients with CTD-related ILD survive longer than those with IIP [20-23]. The
AFFILIATIONS

${ }^{*}$ Dept of Pathophysiology, University of Athens Medical School, and "Laiko University Hospital, Athens, Greece.

CORRESPONDENCE

G.E. Tzelepis

University of Athens Medical School 75 M. Asias Street

11527 Athens

Greece

Fax: 302107462664

E-mail: gtzelep@med.uoa.gr

Received:

May 172007

Accepted after revision:

August 132007

STATEMENT OF INTEREST

None declared.
European Respiratory Journal Print ISSN 0903-1936 Online ISSN 1399-3003 


\begin{tabular}{|c|c|c|c|c|c|c|}
\hline $\begin{array}{l}\text { Types of inte } \\
\text { connective tis }\end{array}$ & ue ditial & $\begin{array}{l}\text { ung dise } \\
\text { seases }\end{array}$ & zase & & ounte & red in \\
\hline & SSc & PM/DM & PSS & RA & SLE & MCTD \\
\hline Usual interstitial pneumonia & + & ++ & + & ++ & + & + \\
\hline $\begin{array}{l}\text { Nonspecific interstitial pneu- } \\
\text { monia }\end{array}$ & ++++ & ++++ & + & + & ++ & + \\
\hline $\begin{array}{l}\text { Cryptogenic organising pneu- } \\
\text { monia }\end{array}$ & + & ++ & + & + & + & - \\
\hline Diffuse alveolar damage & + & ++ & + & + & ++ & - \\
\hline $\begin{array}{l}\text { Lymphocytic interstitial pneu- } \\
\text { monia }\end{array}$ & - & - & +++ & - & - & - \\
\hline
\end{tabular}

SSc: systemic sclerosis; PM: polymyositis; DM: dermatomyositis; PSS: primary Sjögren's syndrome; RA: rheumatoid arthritis; SLE: systemic lupus erythematosus; MCTD: mixed connective tissue disease. +: lowest frequency; ++++: highest frequency; -: rare pulmonary involvement. Reproduced and modified from [12] with permission from the publisher.

difference appears to be related to a better survival of patients with CTD-related UIP rather than to the higher prevalence of NSIP in CTDs [22].

Specific types of CTD-related ILD may present with a fulminant picture and mimic acute respiratory distress syndrome [24]. Although acute presentation of ILD may occur with any CTD, it is more common in systemic lupus erythematosus (SLE) and polymyositis (PM) dermatomyositis (DM), followed by mixed CTD and rheumatoid arthritis (RA).

It is estimated that up to $15-20 \%$ of patients who present with a chronic ILD either have an occult CTD [15] or subsequently develop a clinically overt CTD. In this particular group of patients, the initial clinical presentation may be essentially indistinguishable from that of IIP $[15,18]$. Reporting on 68 patients with IIP followed-up for a period ranging 1-11 yrs, Homma et al. [18] reported on $13(19 \%)$ patients who subsequently developed a CTD. Initial laboratory findings such as levels of antinuclear antibody (ANA) or rheumatoid factor (RF) did not differ between those who did and did not develop a CTD.

How often is CTD-related ILD misclassified as IPF? In a group of patients diagnosed with IPF, FISCHER et al. [25] recently assessed the prevalence of antibodies considered highly specific for scleroderma (those directed against Th/To ribonucleoprotein (anti-Th/To), or ANA with nucleolar staining). In the entire IPF group, $\sim 9 \%$ of patients were found to have one or both types of these antibodies and thus diagnosed as having scleroderma sine scleroderma [25]. Indeed, on retrospective evaluation, most patients with the nucleolar ANA staining, and especially those with positive anti-Th/To antibodies, met criteria for scleroderma sine scleroderma.

Findings favouring CTD-related ILD over IIP are the presence of pleural effusion or significant pleural thickening [26]. Also, biopsy reports consistent with NSIP should raise suspicions about the possibility of an underlying CTD because of the high prevalence of NSIP in CTDs [16, 17, 27-30]. Other biopsy findings that may be suggestive of an underlying CTD include follicular bronchiolitis and lymphoid follicles or pleural lymphoplasmacytic infiltration [16].

In patients presenting with ILD, prompt diagnosis of an occult CTD is crucially important for several reasons. First, it helps the clinician choose the appropriate therapeutic regimen. NSIP related to scleroderma, for example, may require a different therapeutic regimen from the idiopathic form of the disease $[31,32]$. Recent data have shown that, in patients with scleroderma-related ILD, oral cyclophosphamide given for $1 \mathrm{yr}$ results in significant improvements in dyspnoea and health-related quality of life, and modest increases in forced vital capacity and total lung capacity [31]. Owing to the systemic nature of CTDs, a search for additional system involvement (i.e. cardiac in scleroderma) or underlying malignancy (i.e. PM/DM) might also be needed in some cases [20]. Additional advantages of an early diagnosis are fewer diagnostic tests and no need for open lung biopsy when diagnosis is established on the basis of clinical, radiological and laboratory (highly specific autoantibodies) data. Finally, diagnosis of a CTD in this setting enables the clinician to better define disease prognosis and alert the patient about specific complications (i.e. respiratory muscle involvement in PM/DM).

Table 2 illustrates specific CTDs in which chronic ILD may be the sole or predominant manifestation. The clinical characteristics of these diseases are briefly highlighted below. ILD may also occur in SLE. However, the ILD in SLE is typically accompanied by other systemic disease manifestations and does not usually cause diagnostic problems [9, 10, 33, 34].

\section{POLYMYOSITIS/DERMATOMYOSITIS}

$\mathrm{PM} / \mathrm{DM}$ are idiopathic inflammatory myopathies characterised by inflammation and weakness of skeletal muscles, associated, in the case of DM, with characteristic skin manifestations [35].

ILD is one of the major extramuscular manifestations of the disease, occurring at a frequency ranging $5-64 \%$ of patients [20, 36-38]. Although NSIP is the most common pattern [16, 20, 36, 38], COP, diffuse alveolar damage and UIP are also frequently found [16, 20, 36, 38-40]. The diagnosis of PM/DM-related ILD does not pose a diagnostic challenge in patients with established disease or in newly diagnosed patients with typical disease manifestations. However, PM/DM may not be suspected as the underlying cause of ILD when lung involvement is the sole manifestation [20, 38, 41] or when muscle weakness is obscured by incapacitating dyspnoea [20, 38 , 42]. Rarely, in patients with amyopathic DM, the ILD may

TABLE 2 Connective tissue diseases whose interstitial
lung disease may mimic chronic idiopathic
interstitial pneumonia


also create diagnostic difficulties due to the absence of muscle weakness [43].

\section{ILD as the sole PM/DM manifestation}

ILD can be the presenting manifestation in a significant percentage of patients with $\mathrm{PM} / \mathrm{DM}$, with other disease symptoms and signs being minimal or entirely absent $[17,18$, $20,38,44]$. In a series of 70 patients with PM/DM and ILD reported by DougLAs et al. [20], ILD was the sole manifestation in $21(30 \%)$ patients. In an additional 15 patients, there were synchronous respiratory and muscular/cutaneous signs and symptoms. Similar findings were also reported by MARIE et al. [38] in a series of 36 patients with PM/DM-related ILD, with $\sim 20 \%$ of patients initially presenting with lung disease.

Patients initially presenting with only respiratory complaints often have crackles on lung auscultation, and complain of weakness and arthralgias [20]. Joint involvement, particularly in the form of arthralgias, occurs more frequently in patients with ILD than in those without lung involvement $[38,45]$. The diagnosis of PM/DM can be delayed for months or even years after the initial diagnosis of ILD, especially when corticosteroids are used [20, 45].

\section{ILD and amyopathic dermatomyositis}

Amyopathic DM is a discrete subgroup of DM characterised by skin manifestations typical of DM but without muscle weakness [46]. Muscle involvement may never occur [46] or manifest months after the initial skin disease [47]. Although ILD does not usually precede the skin manifestations of DM, the underlying ILD diagnosis may be missed if proper attention is not paid to skin rash [43].

The prevalence of ILD in amyopathic DM ranges 10-20\% [47, 48]. In a meta-analysis of 291 cases of amyopathic DM [47], $13 \%$ of patients had ILD. In six patients with amyopathic DM, KRAIN [48] found two patients with pulmonary fibrosis in whom pulmonary fibrosis had contributed to delay in diagnosis. In a study involving 14 patients with ILD and amyopathic DM, SUDA et al. [43] described two types of ILD, an acute/subacute type with a relatively high mortality and a chronic type. In its rapidly progressive form, the disease may present as diffuse alveolar damage, refractory to high-dose steroids and with a high mortality rate $[43,49,50]$.

\section{Antisynthetase syndrome}

Antisynthetase syndrome refers to a particular group of PM/ DM patients who have specific autoantibodies called antisynthetases. These antibodies are directed against synthetases, the cytoplasmic enzymes facilitating attachment of amino acids to their correspondent transfer RNAs (tRNAs). Clinical characteristics of the syndrome include myositis, Raynaud's phenomenon, fever, mechanic's hands and arthralgias [51-53]. With an incidence ranging $75-100 \%$ [51, 54, 55], ILD does not differ in presenting symptoms and histological appearance from ILD of other aetiologies, and is the main cause of morbidity and mortality in these patients [56].

Of all antisynthetase antibodies, one directed against histidyl transfer RNA synthetase (anti-Jo-1) is the most commonly detected. Since these antibodies are very specific, their presence is of high diagnostic significance. This can be especially helpful in cases in which one or more of the clinical manifestations of antisynthetase syndrome do not temporally coincide with ILD (fig. 1) [53, 57-59]. In some cases [55, 58], myositis may follow years after autoantibody detection, whereas, in others, no clinical myositis ensues during the observation period [53]. In patients with less common antisynthetases (i.e. directed against alanyl tRNA synthetase (PL-12)), ILD may be the sole manifestation of the syndrome [57].

\section{SCLERODERMA}

Scleroderma or systemic sclerosis (SSc) is a multisystemic disease of unknown aetiology characterised by fibrosis of the skin and internal organs [60]. Associated more often with the diffuse than the limited form of SSc, ILD is one of the major causes of SSc-related mortality. Although the overall prevalence of ILD varies depending upon the method used and population studied, its estimated range is 70-80\% [61-63]. The diagnostic challenge of ILD-related SSc lies in the fact that skin involvement, which is the trademark of the disease, may be either entirely absent (scleroderma sine scleroderma) or very subtle, as may occur in some forms of limited scleroderma with anti-Th/To antibodies.
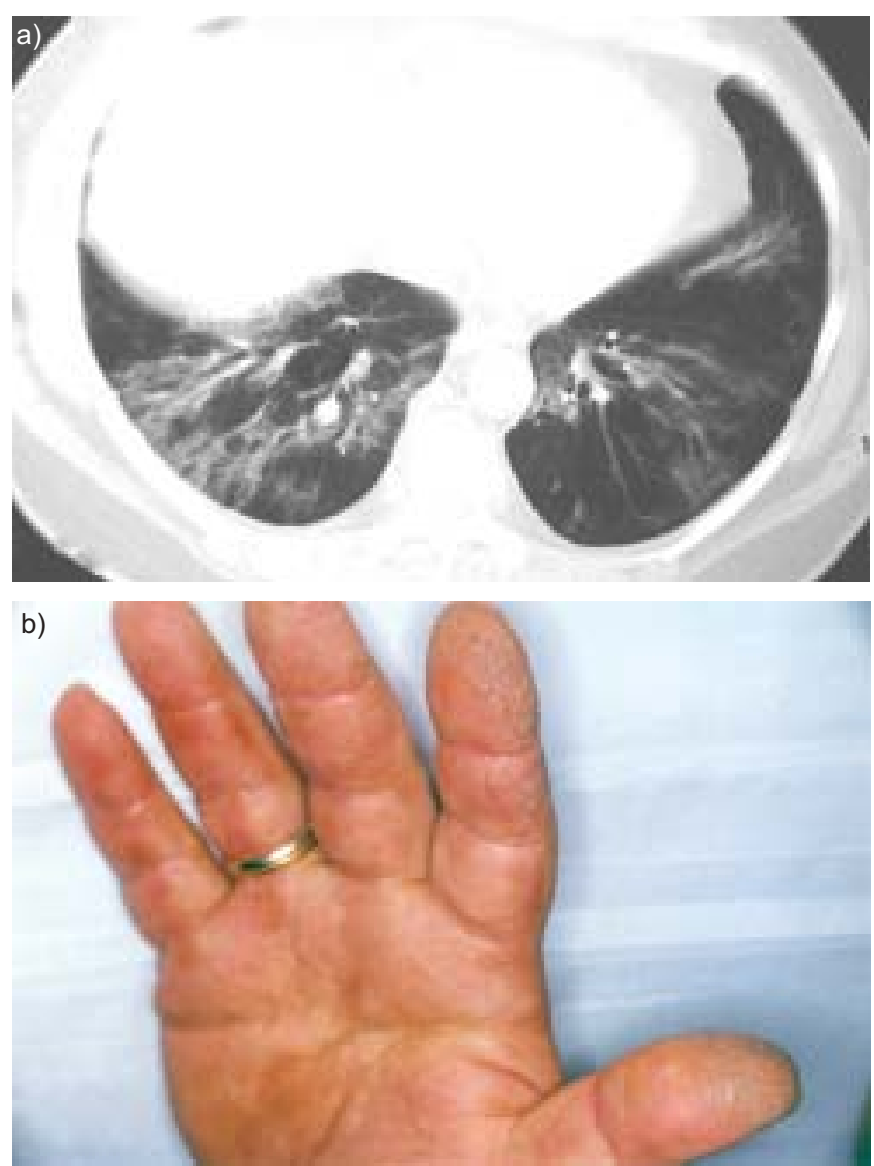

FIGURE 1. a) Lung computed tomography of a patient with antisynthetase syndrome and histidyl transfer RNA synthetase (Jo-1) antibodies. The patient presented with dyspnoea and cough; the correct diagnosis was made with a 6month delay, when the patient developed the characteristic hand rash (mechanic's hands; b) 


\section{Scleroderma sine scleroderma}

In this particular group of SSc patients, ILD may occur without skin thickening and may be the predominant or sole manifestation [32, 64-67].

Originally described by RODNAN and FENNELL [68] $>40$ yrs ago, scleroderma sine scleroderma is essentially a variant of limited scleroderma with an estimated prevalence of approximately one tenth of that of the limited disease subtype [69]. ILD occurs in $>80 \%$ of patients with scleroderma sine scleroderma and may be confused with IPF. The histological and radiological features are those of NSIP (fig. 2) or UIP [32]. The clinician may suspect the entity by certain characteristic findings suggestive of systemic involvement. Most patients show scattered telangiectasias, Raynaud's phenomenon, oesophageal reflux disease, abnormal nail capillaroscopy or asymptomatic pericardial effusion on echocardiographic examination [32, 65]. ANAs are found in the majority of cases $(>93 \%)[32,69]$, with the most frequent type being non-SSc-associated autoantibodies followed by anticentromere antibodies; anti-topoisomerase I or anti-Th/To may be detected less frequently [69]. Reporting on 48 patients with scleroderma sine scleroderma, POORMOGHIM et al. [69] have suggested that the disease should be considered in the presence of the following features. 1) Raynaud's phenomenon or a peripheral vascular equivalent, such as digital pitting scars, digital tip ulcers, digital tip gangrene or abnormal capillaries. 2) Positive ANA results. 3) Any one of the following: distal oesophageal hypomotility, small bowel hypomotility, pulmonary fibrosis, pulmonary arterial hypertension without fibrosis, cardiac involvement typical of scleroderma, or renal failure consistent with sclerodermic renal crisis, and no other CTD or disease that would explain these findings.

\section{Limited scleroderma with antibodies directed against Th/To ribonucleoprotein}

In some patients with limited scleroderma, the presence of anti-Th/To antibodies may be associated with minimal skin

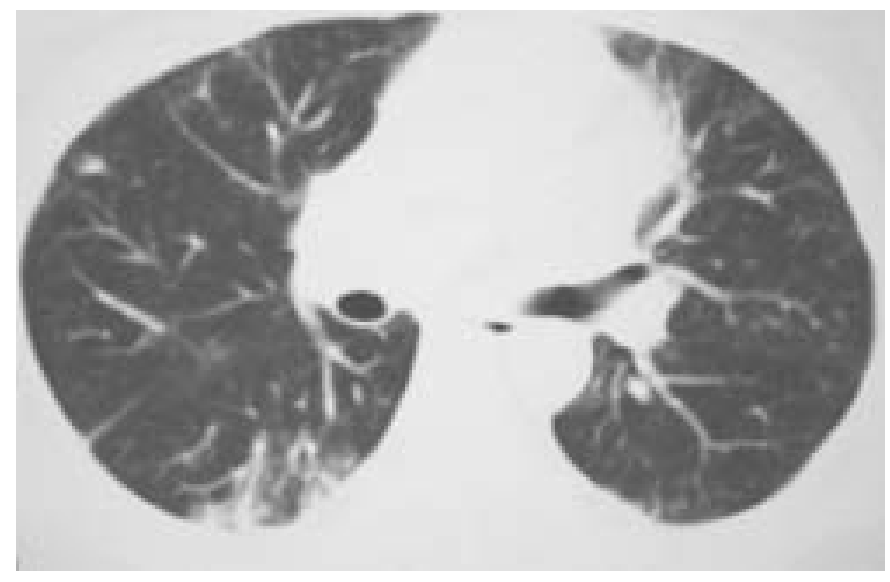

FIGURE 2. Lung computed tomographic appearance of biopsy-proven nonspecific interstitial pneumonia (NSIP) in a patient with scleroderma sine scleroderma. The patient, who had history of oesophageal reflux disease, presented with dyspnoea on exertion. The initial diagnosis was idiopathic NSIP; within the ensuing year, the patient developed Raynaud's phenomenon and an asymptomatic pericardial effusion. Laboratory testing revealed antinuclear antibody (dilution 1/1,280) with a nucleolar pattern. thickening and relatively less prominent vascular disease. These two clinical features occur comparatively less than in the classic form of limited scleroderma. Pulmonary fibrosis is seen more frequently than in anticentromere-positive patients (48 versus $13 \%$ ) and is the second most common cause of death in these patients [70]. Owing to subtle skin changes, the diagnosis of scleroderma can be easily missed in patients presenting with ILD-related symptoms [70].

Anti-Th/To antibodies are directed against a group of RNA processing enzymes [71] and occur in $4-13 \%$ of SSc patients, mostly in those with limited disease [70, 72]. Although testing for anti-Th/To antibodies is not commercially available, their presence may be a useful marker for underlying scleroderma sine scleroderma in a patient with ILD [32]. On ANA staining, they produce a bright nucleolar or nucleolar plus speckled pattern. As with scleroderma sine scleroderma, the diagnosis should be suspected in patients with Raynaud's phenomenon, telangiectasias, digital tip ulcers, oesophageal hypomotility, cardiac involvement and a positive ANA result with a bright nucleolar or nucleolar plus speckled pattern [70].

\section{RHEUMATOID ARTHRITIS}

$\mathrm{RA}$ is a systemic autoimmune disorder characterised by widespread joint inflammation with synovial hyperplasia. The disease affects $1-2 \%$ of the population and is frequently associated with extra-articular manifestations in the skin, eye, heart and lung $[73,74]$.

ILD is the commonest and most serious pulmonary complication of RA; it affects $\sim 15-20 \%$ of patients with RA, although higher prevalence rates are reported when different methods of detection are employed [13, 75-79]. The most prevalent histological pattern is UIP followed by NSIP; COP may also occur but less frequently [13, 14, 79, 80].

In $\sim 90 \%$ of RA patients, ILD poses no diagnostic difficulties because it follows the onset of joint symptoms by a few years $[75,81]$; in some cases, joint involvement, albeit present, might be overlooked due to decreased mobility related to pulmonary impairment. However, in $\sim 10 \%$ of cases, ILD may be the first manifestation of RA, especially that with the histological pattern of NSIP [10, 79, 82]. In this setting, the aetiological diagnosis of ILD is difficult and indistinguishable from that of IIP. In a small proportion of RA patients with ILD but no joint involvement, subcutaneous nodules may be present and suggest the presence of a systemic disease. In a study of 18 patients with RA-related ILD reported by LEE et al. [82], ILD preceded RA diagnosis in three patients by 1.6, 2.5 and 7 yrs, respectively, whereas, in another three patients, the diagnosis of ILD and RA occurred simultaneously.

Detection of cyclic citrullinated peptide (CCP) antibodies, which has recently become available, may help diagnostically in cases in which ILD precedes the arthritic manifestations of RA. These antibodies are directed against the citrullinated proteins, such as fillagrin and its circular form, CCP. Anti-CCP antibodies are detected in the serum of asymptomatic blood donors years before the clinical diagnosis of RA is made [83]. Also, in patients with early undifferentiated arthritis, anti-CCP antibodies are very strong predictors for subsequent development of RA and joint destruction [84]. Owing to their high specificity and sensitivity, especially when combined with 
positive RF results, anti-CCP antibodies may become a useful tool for establishing a diagnosis of RA.

\section{SJÖGREN'S SYNDROME}

Sjögren's syndrome (SS) is a chronic autoimmune disorder characterised by lymphocytic infiltration of the exocrine glands and epithelium of various organs. A primary, or secondary in conjunction with other autoimmune diseases, disorder, SS occurs in $0.1-1 \%$ of the population $[85,86]$. Respiratory system involvement in primary SS mainly manifests as small airway disease, large airway obstruction or desiccation of the tracheobronchial tree [87, 88].

ILD may also occur in primary SS (fig. 3) but less frequently than the airway manifestations [13]. Although its exact prevalence is not known, it is probably $<5 \%$ [13, 89-91]. Early studies considered LIP and primary pulmonary lymphoma as the most common forms of parenchymal disease in primary SS, whereas UIP and NSIP were considered rare. However, recent studies $[91,92]$ have reported that NSIP and, less frequently, UIP may also occur in primary SS. ITO et al. [92] reported that NSIP was the most common histological pattern, found in $60 \%$ of patients with SS and ILD. In a similar study involving 18 patients with primary SS and ILD [91], NSIP was also the predominant histopathological type, followed by UIP and LIP. Notably, in the study of ITO et al. [92], no case with a histological LIP pattern was detected.

Although exceedingly rare, the patient with primary SS may present with radiological and physiological findings consistent with ILD but without prominent sicca symptoms [88]. This occurs especially frequently in older patients, who tend to dismiss sicca symptoms as age-related. In this case, specific questioning regarding sicca-associated symptoms should be sought or a specific sicca-associated questionnaire should be filled in by every patient presenting with ILD. If clinically suspected, the diagnosis of ILD-SS can be established by specific tests, including lip biopsy and serology. These patients almost invariably exhibit positive ANA results; specific autoantibodies, such as anti-SSA and anti-SSB, are also detected in $70-90 \%$ of cases [91].

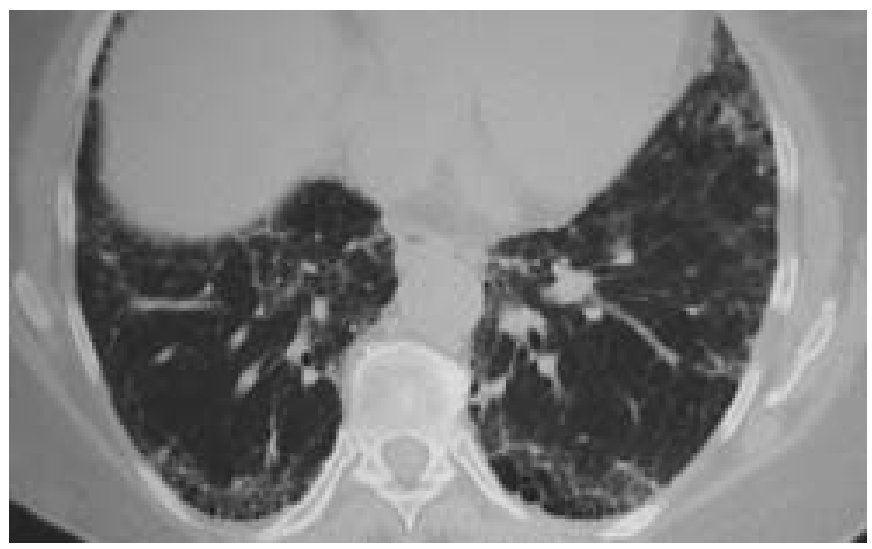

FIGURE 3. Thoracic computed tomography showing a usual interstitial pneumonia pattern in a patient with Sjögren's syndrome and interstitial lung disease. The patient presented with dyspnoea and cough; sicca symptoms were also present.

\section{MIXED CTD}

Mixed CTD (MCTD) is a disease characterised by overlapping features of SLE, SSc and PM, and high titres of autoantibodies directed against U1 small nuclear ribonucleoprotein (RNP). Common clinical features include Raynaud's phenomenon, swollen hands, arthritis, sclerodactyly, myositis and ILD; pulmonary hypertension and pleural effusions may also occur [93-95].

ILD is estimated to occur in up to $65 \%$ of patients with MCTD [95]; its major histopathological pattern is that of NSIP, as suggested by histological and radiological data [12, 22, 96]. It typically manifests within the first $2-4$ yrs following disease onset, when other systemic manifestations of SLE, SSc or PM are also present as the disease progresses [93, 95]. Rarely, the ILD-related symptoms may be the predominant or first manifestation of the disease [96]. In a group of 35 patients with MCTD and ILD undergoing thoracic imaging, SAITO et al. [96] reported three patients with only respiratory problems, who were initially believed to have IPF but later diagnosed with MCTD.

In the majority of MCTD-related ILD cases, there appears to be no diagnostic difficulty in identifying the systemic nature of the illness. In the rare case in which ILD symptomatology predominates the clinical picture, the high titre of anti-RNP (dilution $>1: 1,600$ ) provides a clue to the disease [97].

\section{UNDIFFERENTIATED CTD}

Undifferentiated CTD (UCTD) includes those patients with some clinical and serological characteristics suggestive of autoimmune disease, yet insufficient to make a diagnosis of a specific CTD $[98,99]$. These patients may not necessarily progress to a specific CTD $[98,99]$. Nonpulmonary symptoms may be subtle and include arthralgias or arthritis, Raynaud's phenomenon and haematological abnormalities, including anaemia or leukopenia, and sicca symptoms [98, 99]. Of the patients, $\sim 90 \%$ are ANA-positive and, in the majority of cases, there is single antibody positivity, usually of anti-SSA/Ro or anti-RNP antibodies [100].

In the absence of diagnostic criteria [98], the diagnosis of UCTD and its aetiological association with ILD can be contentious. It is quite possible that the ILD, in this setting, is misclassified as IIP [101, 102]. In a recent study, KINDER et al. [102] assessed the prevalence of UCTD in a group of patients with IIP. Using a predefined set of criteria (i.e. combination of clinical and serological markers), they found that $\sim 10 \%$ of IIP patients met criteria for UCTD. These patients were typically younger, female and nonsmokers, and, in the majority of them, the histological pattern was NSIP. These findings prompted the authors to propose that the so-called idiopathic NSIP may in fact be the pulmonary manifestation of a generalised autoimmune process.

\section{PHYSICAL EXAMINATION}

Review of systems, in conjunction with a comprehensive physical examination, may yield significant clues to an underlying CTD. Table 3 presents symptoms and physical findings commonly associated with CTDs. Raynaud's phenomenon in a patient with ILD invariably indicates an autoimmune disease. Since Raynaud's phenomenon is found 
in $>90 \%$ of patients with scleroderma sine scleroderma, its absence should make this diagnosis less likely [32, 69]. If scleroderma sine scleroderma is suspected, the search for telangiectasias should be thorough and include face, lips, palms and mucous membranes. As with Raynaud's phenomenon, digital tip ulcers or pitting scars are signs suggestive of vasculopathy. Puffy fingers are frequently seen in patients with occult CTD.

Arthralgias without synovitis may occur in patients with IPF, whereas active arthritis suggests an underlying CTD. Clubbing, which is found in $>50 \%$ of IPF patients, is also seen in RA-related ILD and less frequently in PM/DM. The characteristic skin rashes of DM include the violaceous scaly patches found over bony prominences, the violaceous (heliotrope) discoloration of eyelids and Gottron's papules. Mechanic's hands (fig. 1), which is pathognomonic for antisynthetase syndrome, consists of a thick and fissured skin texture involving the palmar surfaces of both hands.

Gastro-oesophageal reflux disease is present in up to $20 \%$ of the healthy adult population [103, 104]. It is very common in

\begin{tabular}{l} 
TABLE 3 Symptoms and signs associated with connective \\
tissue diseases \\
Joint and muscle \\
Arthralgias \\
Arthritis \\
Morning stiffness \\
Synovitis \\
Myalgias \\
Muscular weakness \\
Skin \\
Raynaud's phenomenon \\
Digital ulcers \\
Pitting scars \\
Telangiectasias \\
Sclerodactyly \\
Puffy hands \\
Malar rash \\
Photosensitivity \\
Heliotrope rash \\
Mechanic's hands \\
Gottron's papules \\
Subcutaneous nodules \\
Gastrointestinal \\
Dry mouth \\
Mouth ulcers \\
Oesophageal reflux or hypomotility \\
Dysphagia \\
Abdominal bloating \\
Ophthalmological \\
Dry eyes \\
Corneal ulcers \\
Uveitis \\
Scleritis \\
Pleuritis \\
Pericarditis \\
\hline
\end{tabular}

patients with IPF, with the reported prevalence being $>80 \%$ [105]. Since gastro-oesophageal reflux disease may occur due to underlying scleroderma, special consideration should be given to this symptom, which should not be dismissed as insignificant. For example, in patients with scleroderma sine scleroderma, gastrointestinal involvement occurs in $\sim 80 \%$ of patients $[32,69,105]$.

\section{LABORATORY FINDINGS}

In the patient with ILD and suspicion of an occult CTD, specific laboratory testing tailored to clinical impression is required to rule out a systemic disease. In general, laboratory tests are not highly sensitive or specific for accurate diagnosis of CTDs. However, in conjunction with clinical evidence, these tests may provide a high degree of confidence regarding the presence of a CTD. In addition to routine laboratory testing, such as complete blood count, urinalysis, erythrocyte sedimentation rate and measurement of C-reactive protein and serum immunoglobulins, levels of the muscle enzymes creatine phosphokinase and aldolase should form part of the initial laboratory panel. A comprehensive, but by no means complete, list of laboratory tests is shown in table 4 .

Autoantibody testing plays a central role in both screening for and diagnosis of CTDs. Since these tests have limitations and their use may lead to erroneous conclusions, interpretations should always be made in conjunction with the clinical picture. ANAs are usually detected by indirect immunofluorescence after sera incubation with fixed Hep-2 cells. They are useful in the initial screening process and may provide information about the presence of other autoantibodies that need to be detected. The ANA results (titre and pattern) are subjective and may vary between laboratories depending upon experience. In addition to clinical findings, interpretation of a positive ANA test result needs to take into consideration the patient's age and antibody titre. Positive ANA testing is also associated with infections, drug therapy and various inflammatory diseases. It should be noted that ANA titre is not a marker of disease activity. In general, the higher the titre the more likely it is that a CTD is present. Low ANA titres

\begin{tabular}{l} 
TABLE 4 Laboratory evaluation of the patient with \\
$\begin{array}{l}\text { connective tissue disease-related interstitial lung } \\
\text { disease }\end{array}$ \\
Routine \\
$\begin{array}{l}\text { Complete cell count; electrolytes; blood urea nitrogen; } \\
\text { creatinine; liver function tests; urinalysis; CPK; } \\
\text { aldolase; ESR; CRP; serum immunoglobulins; ECG; } \\
\text { echocardiography } \\
\text { ANAs with pattern, titre and ENAs; RF; anti-CCP antibody; } \\
\text { anti-SSA/SSB antibodies (Ro/La); anti-Scl-70; } \\
\text { anticentromere antibody; Jo-1 antibody; anti-Mi-2 } \\
\text { antibody; anti-RNP }\end{array}$ \\
\hline
\end{tabular}

CPK: creatine phosphokinase; ESR: erythrocyte sedimentation rate; CRP: Creactive protein; ANA: antinuclear antibody; ENA: extractable nuclear antigen; RF: rheumatoid factor; CCP: cyclic citrullinated peptide; SS: Sjögren's syndrome; Scl: scleroderma; Jo-1: histidyl transfer RNA synthetase; Mi-2: Mi2 nuclear antigen; RNP: ribonucleoprotein. 


\begin{tabular}{|c|c|c|c|c|c|c|}
\hline \multirow[t]{2}{*}{ TABLE 5} & \multicolumn{6}{|c|}{$\begin{array}{l}\text { Autoantibody prevalences by disease } \\
\text { association }\end{array}$} \\
\hline & SLE & RA & SSc & PM/DM & PSS & MCTD \\
\hline ANA & $90-98$ & 40 & 96 & 25-90 & 70-95 & 93 \\
\hline Anti-dsDNA & $50-80$ & & & & & \\
\hline Anti-Smith & $20-30$ & & & & & \\
\hline RF & $15-25$ & $65-90$ & $10-50$ & $10-40$ & $30-70$ & \\
\hline Anti-SSA/Ro & $20-30$ & & & & 50-90 & \\
\hline Anti-SSB/La & $10-20$ & & & & 50 & \\
\hline \multirow{2}{*}{ Anti-Scl-70 } & & & $30-35^{\#}$ & & & \\
\hline & & & $10-20^{\circ}$ & & & \\
\hline ACA & & & $40-80^{\circ}$ & & & \\
\hline Anti-Jo-1 & & & & $10-50$ & & \\
\hline Anti-RNP & $30-40$ & & & & & 100 \\
\hline Anti-CCP & & 50-75 & & & & \\
\hline \multicolumn{7}{|c|}{ 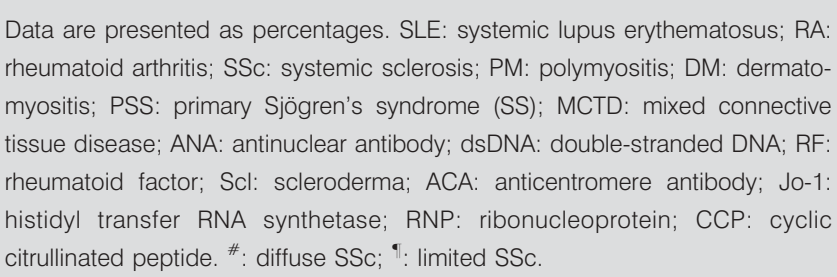 } \\
\hline
\end{tabular}

(dilution $<1: 160$ ) occur in $\sim 10-20 \%$ of patients with IPF [101]. In contrast, a negative ANA test result does not necessarily exclude a CTD.

Specific autoantibody testing for an extractable nuclear antigen (ENA) should supplant positive ANA testing. Table 5 shows the most clinically useful specific autoantibodies with their disease associations and prevalence. Of these autoantibodies, anti-SSA/Ro and anti-SSB/La should be determined separately, even in the absence of a positive ANA result, when SS is clinically suspected [106, 107]. The presence of these autoantibodies in the appropriate setting is highly specific for a CTD.

ANA staining patterns are currently less important due to the ability to detect specific ENAs. However, they continue to be relevant since they might provide a clue to the presence of less typical ENAs, which might not be incorporated into routine anti-ENA testing [108]. An example is detection of a nucleolar staining pattern, which is highly specific for scleroderma.

\section{CONCLUSION}

An occult connective tissue disease should be considered in every patient presenting with interstitial lung disease-related symptomatology. Connective tissue diseases that may mimic chronic idiopathic interstitial pneumonias include rheumatoid arthritis, polymyositis/dermatomyositis, scleroderma, Sjögren's syndrome, mixed connective tissue disease and undifferentiated connective tissue disease. A high index of suspicion is required for patients with lung biopsy results consistent with nonspecific interstitial pneumonia. In order to exclude a subclinical connective tissue disease, the clinical examination should be thorough and include a search for signs of systemic disease in various organs, including skin and vascular and musculoskeletal system. In most cases, immunological testing is required to confirm the connective tissue disease diagnosis.

\section{REFERENCES}

1 American Thoracic Society, European Respiratory Society. American Thoracic Society/European Respiratory Society International Multidisciplinary Consensus Classification of the Idiopathic Interstitial Pneumonias. Am J Respir Crit Care Med 2002; 165: 277-304.

2 Raghu G, Brown KK. Interstitial lung disease: clinical evaluation and keys to an accurate diagnosis. Clin Chest Med 2004; 25: 409-419: v.

3 Bjoraker JA, Ryu JH, Edwin MK, et al. Prognostic significance of histopathologic subsets in idiopathic pulmonary fibrosis. Am J Respir Crit Care Med 1998; 157: 199-203.

4 Katzenstein AL, Myers JL. Idiopathic pulmonary fibrosis: clinical relevance of pathologic classification. Am J Respir Crit Care Med 1998; 157: 1301-1315.

5 Martinez FJ, Safrin S, Weycker D, et al. The clinical course of patients with idiopathic pulmonary fibrosis. Ann Intern Med 2005; 142: 963-967.

6 Coultas DB, Zumwalt RE, Black WC, Sobonya RE. The epidemiology of interstitial lung diseases. Am J Respir Crit Care Med 1994; 150: 967-972.

7 Reynolds HY. Diagnostic and management strategies for diffuse interstitial lung disease. Chest 1998; 113: 192-202.

8 Flaherty KR, Andrei AC, King TE Jr, et al. Idiopathic interstitial pneumonia: do community and academic physicians agree on diagnosis? Am J Respir Crit Care Med 2007; 175: 1054-1060.

9 Crestani B. The respiratory system in connective tissue disorders. Allergy 2005; 60: 715-734.

10 Hunninghake GW, Fauci AS. Pulmonary involvement in the collagen vascular diseases. Am Rev Respir Dis 1979; 119: 471-503.

11 Wiedemann HP, Matthay RA. Pulmonary manifestations of the collagen vascular diseases. Clin Chest Med 1989; 10 677-722.

12 Kim EA, Lee KS, Johkoh T, et al. Interstitial lung diseases associated with collagen vascular diseases: radiologic and histopathologic findings. Radiographics 2002; 22: S151-S165.

13 Lamblin C, Bergoin C, Saelens T, Wallaert B. Interstitial lung diseases in collagen vascular diseases. Eur Respir J 2001; 18: Suppl. 32, 69s-80s.

14 Nicholson AG, Colby TV, Wells AU. Histopathological approach to patterns of interstitial pneumonia in patient with connective tissue disorders. Sarcoidosis Vasc Diffuse Lung Dis 2002; 19: 10-17.

15 Strange $C$, Highland $K B$. Interstitial lung disease in the patient who has connective tissue disease. Clin Chest Med 2004; 25: 549-559: vii.

16 Tansey D, Wells AU, Colby TV, et al. Variations in histological patterns of interstitial pneumonia between connective tissue disorders and their relationship to prognosis. Histopathology 2004; 44: 585-596.

17 Fujita J, Ohtsuki Y, Yoshinouchi T, et al. Idiopathic nonspecific interstitial pneumonia: as an "autoimmune interstitial pneumonia". Respir Med 2005; 99: 234-240. 
18 Homma Y, Ohtsuka Y, Tanimura K, et al. Can interstitial pneumonia as the sole presentation of collagen vascular diseases be differentiated from idiopathic interstitial pneumonia? Respiration 1995; 62: 248-251.

19 Felicio $\mathrm{CH}$, Parra ER, Capelozzi VL. Idiopathic and collagen vascular disease nonspecific interstitial pneumonia: clinical significance of remodeling process. Lung 2007; 185: 39-46.

20 Douglas WW, Tazelaar HD, Hartman TE, et al. Polymyositis-dermatomyositis-associated interstitial lung disease. Am J Respir Crit Care Med 2001; 164: 1182-1185.

21 Flaherty KR, Colby TV, Travis WD, et al. Fibroblastic foci in usual interstitial pneumonia: idiopathic versus collagen vascular disease. Am J Respir Crit Care Med 2003; 167: 1410-1415.

22 Park JH, Kim DS, Park IN, et al. Prognosis of fibrotic interstitial pneumonia: idiopathic versus collagen vascular disease-related subtypes. Am J Respir Crit Care Med 2007; 175: 705-711.

23 Wells AU, Cullinan P, Hansell DM, et al. Fibrosing alveolitis associated with systemic sclerosis has a better prognosis than lone cryptogenic fibrosing alveolitis. Am J Respir Crit Care Med 1994; 149: 1583-1590.

24 Schwarz MI, Albert RK. "Imitators" of the ARDS: implications for diagnosis and treatment. Chest 2004; 125: 1530-1535.

25 Fischer A, Pfalzgraf FJ, Feghali-Bostwick CA, et al. AntiTh/To-positivity in a cohort of patients with idiopathic pulmonary fibrosis. J Rheumatol 2006; 33: 1600-1605.

26 Highland KB, Heffner JE. Pleural effusion in interstitial lung disease. Curr Opin Pulm Med 2004; 10: 390-396.

27 Cottin V, Donsbeck AV, Revel D, et al. Nonspecific interstitial pneumonia. Individualization of a clinicopathologic entity in a series of 12 patients. Am J Respir Crit Care Med 1998; 158: 1286-1293.

28 Cottin V, Thivolet-Bejui F, Reynaud-Gaubert M, et al. Interstitial lung disease in amyopathic dermatomyositis, dermatomyositis and polymyositis. Eur Respir J 2003; 22: 245-250.

29 Bouros D, Wells AU, Nicholson AG, et al. Histopathologic subsets of fibrosing alveolitis in patients with systemic sclerosis and their relationship to outcome. Am J Respir Crit Care Med 2002; 165: 1581-1586.

30 Nakamura Y, Chida K, Suda T, et al. Nonspecific interstitial pneumonia in collagen vascular diseases: comparison of the clinical characteristics and prognostic significance with usual interstitial pneumonia. Sarcoidosis Vasc Diffuse Lung Dis 2003; 20: 235-241.

31 Tashkin DP, Elashoff R, Clements PJ, et al. Cyclophosphamide versus placebo in scleroderma lung disease. $N$ Engl J Med 2006; 354: 2655-2666.

32 Fischer A, Meehan RT, Feghali-Bostwick CA, et al. Unique characteristics of systemic sclerosis sine sclerodermaassociated interstitial lung disease. Chest 2006; 130: 976-981.

33 Cheema GS, Quismorio FP Jr. Interstitial lung disease in systemic lupus erythematosus. Curr Opin Pulm Med 2000; 6: 424-429.

34 Eisenberg $\mathrm{H}$, Dubois EL, Sherwin RP, Balchum OJ. Diffuse interstitial lung disease in systemic lupus erythematosus. Ann Intern Med 1973; 79: 37-45.
35 Dalakas MC, Hohlfeld R. Polymyositis and dermatomyositis. Lancet 2003; 362: 971-982.

36 Arakawa H, Yamada H, Kurihara Y, et al. Nonspecific interstitial pneumonia associated with polymyositis and dermatomyositis: serial high-resolution CT findings and functional correlation. Chest 2003; 123: 1096-1103.

37 Imbert-Masseau A, Hamidou M, Agard C, et al. Antisynthetase syndrome. Joint Bone Spine 2003; 70: 161-168.

38 Marie I, Hachulla E, Cherin P, et al. Interstitial lung disease in polymyositis and dermatomyositis. Arthritis Rheum 2002; 47: 614-622.

39 Fathi M, Lundberg IE. Interstitial lung disease in polymyositis and dermatomyositis. Curr Opin Rheumatol 2005; 17: 701-706.

40 Kang EH, Lee EB, Shin KC, et al. Interstitial lung disease in patients with polymyositis, dermatomyositis and amyopathic dermatomyositis. Rheumatology (Oxford) 2005; 44: 1282-1286.

41 Fujisawa T, Suda T, Nakamura Y, et al. Differences in clinical features and prognosis of interstitial lung diseases between polymyositis and dermatomyositis. J Rheumatol 2005; 32: 58-64.

42 Clawson K, Oddis CV. Adult respiratory distress syndrome in polymyositis patients with the anti-Jo-1 antibody. Arthritis Rheum 1995; 38: 1519-1523.

43 Suda T, Fujisawa T, Enomoto N, et al. Interstitial lung diseases associated with amyopathic dermatomyositis. Eur Respir J 2006; 28: 1005-1012.

44 Sato T, Fujita J, Yamadori I, et al. Non-specific interstitial pneumonia; as the first clinical presentation of various collagen vascular disorders. Rheumatol Int 2006; 26: 551-555.

45 Schnabel A, Reuter M, Biederer J, et al. Interstitial lung disease in polymyositis and dermatomyositis: clinical course and response to treatment. Semin Arthritis Rheum 2003; 32: 273-284.

46 el-Azhary RA, Pakzad SY. Amyopathic dermatomyositis: retrospective review of 37 cases. J Am Acad Dermatol 2002; 46: 560-565.

47 Gerami P, Schope JM, McDonald L, et al. A systematic review of adult-onset clinically amyopathic dermatomyositis (dermatomyositis sine myositis): a missing link within the spectrum of the idiopathic inflammatory myopathies. J Am Acad Dermatol 2006; 54: 597-613.

48 Krain L. Dermatomyositis in six patients without initial muscle involvement. Arch Dermatol 1975; 111: 241-245.

49 Miyazaki E, Ando M, Muramatsu T, et al. Early assessment of rapidly progressive interstitial pneumonia associated with amyopathic dermatomyositis. Clin Rheumatol 2007; 26: 436-439.

50 Sakamoto N, Mukae H, Fujii T, et al. Nonspecific interstitial pneumonia with poor prognosis associated with amyopathic dermatomyositis. Intern Med 2004; 43: 838-842.

51 Marguerie C, Bunn CC, Beynon HL, et al. Polymyositis, pulmonary fibrosis and autoantibodies to aminoacyltRNA synthetase enzymes. Q J Med 1990; 77: 1019-1038.

52 Ohosone $Y$, Ishida M, Takahashi $Y$, et al. Spectrum and clinical significance of autoantibodies against transfer RNA. Arthritis Rheum 1998; 41: 1625-1631. 
53 Sauty A, Rochat T, Schoch OD, et al. Pulmonary fibrosis with predominant CD8 lymphocytic alveolitis and antiJo-1 antibodies. Eur Respir J 1997; 10: 2907-2912.

54 Bernstein RM, Morgan SH, Chapman J, et al. Anti-Jo-1 antibody: a marker for myositis with interstitial lung disease. BMJ (Clin Res Ed) 1984; 289: 151-152.

55 Chmiel JF, Wessel HU, Targoff IN, Pachman LM. Pulmonary fibrosis and myositis in a child with anti-Jo1 antibody. J Rheumatol 1995; 22: 762-765.

56 Love LA, Leff RL, Fraser DD, et al. A new approach to the classification of idiopathic inflammatory myopathy: myositis-specific autoantibodies define useful homogeneous patient groups. Medicine (Baltimore) 1991; 70: 360-374.

57 Friedman AW, Targoff IN, Arnett FC. Interstitial lung disease with autoantibodies against aminoacyl-tRNA synthetases in the absence of clinically apparent myositis. Semin Arthritis Rheum 1996; 26: 459-467.

58 Nash P, Schrieber L, Webb J. Interstitial lung disease as the presentation of anti-Jo-1 positive polymyositis. Clin Rheumatol 1987; 6: 282-286.

59 Plastiras SC, Soliotis FC, Vlachoyiannopoulos P, Tzelepis GE. Interstitial lung disease in a patient with antisynthetase syndrome and no myositis. Clin Rheumatol 2007; 26: 108-111.

60 Steen VD. Systemic sclerosis. Rheum Dis Clin North Am 1990; 16: 641-654.

61 D'Angelo WA, Fries JF, Masi AT, Shulman LE. Pathologic observations in systemic sclerosis (scleroderma). A study of fifty-eight autopsy cases and fifty-eight matched controls. Am J Med 1969; 46: 428-440.

62 Plastiras SC, Karadimitrakis SP, Ziakas PD, et al. Scleroderma lung: initial forced vital capacity as predictor of pulmonary function decline. Arthritis Rheum 2006; 55: 598-602.

63 Steen VD, Owens GR, Fino GJ, et al. Pulmonary involvement in systemic sclerosis (scleroderma). Arthritis Rheum 1985; 28: 759-767.

64 Ferri C, Bernini L, Gremignai G, et al. Lung involvement in systemic sclerosis sine scleroderma treated by plasma exchange. Int J Artif Organs 1992; 15: 426-431.

65 Lomeo RM, Cornella RJ, Schabel SI, Silver RM. Progressive systemic sclerosis sine scleroderma presenting as pulmonary interstitial fibrosis. Am J Med 1989; 87: 525-527.

66 Slobodin G, Rosner I, Rozenbaum M, et al. Systemic sclerosis sine scleroderma: is it always the same disease? Report of three patients and discussion. Rheumatol Int 2002; 22: 170-172.

67 Vano SD, Arranz GG, Yglesias PJ. Systemic sclerosis sine scleroderma presenting as pulmonary intersticial fibrosis. Clin Rheumatol 2006; 25: 382-383.

68 Rodnan GP, Fennell RH Jr. Progressive systemic sclerosis sine scleroderma. JAMA 1962; 180: 665-670.

69 Poormoghim H, Lucas M, Fertig N, Medsger TA Jr. Systemic sclerosis sine scleroderma: demographic, clinical, and serologic features and survival in forty-eight patients. Arthritis Rheum 2000; 43: 444-451.

70 Mitri GM, Lucas M, Fertig N, et al. A comparison between anti-Th/To- and anticentromere antibody-positive systemic sclerosis patients with limited cutaneous involvement. Arthritis Rheum 2003; 48: 203-209.

71 Reddy R, Tan EM, Henning D, et al. Detection of a nucleolar 7-2 ribonucleoprotein and a cytoplasmic 8-2 ribonucleoprotein with autoantibodies from patients with scleroderma. J Biol Chem 1983; 258: 1383-1386.

72 Okano Y, Medsger TA Jr. Autoantibody to Th ribonucleoprotein (nucleolar 7-2 RNA protein particle) in patients with systemic sclerosis. Arthritis Rheum 1990; 33: 1822-1828.

73 Gabriel SE. The epidemiology of rheumatoid arthritis. Rheum Dis Clin North Am 2001; 27: 269-281.

74 Spector TD. Rheumatoid arthritis. Rheum Dis Clin North Am 1990; 16: 513-537.

75 Anaya JM, Diethelm L, Ortiz LA, et al. Pulmonary involvement in rheumatoid arthritis. Semin Arthritis Rheum 1995; 24: 242-254.

76 Dawson JK, Fewins HE, Desmond J, et al. Fibrosing alveolitis in patients with rheumatoid arthritis as assessed by high resolution computed tomography, chest radiography, and pulmonary function tests. Thorax 2001; 56: 622-627.

77 Gabbay E, Tarala R, Will R, et al. Interstitial lung disease in recent onset rheumatoid arthritis. Am J Respir Crit Care Med 1997; 156: 528-535.

78 Tanoue LT. Pulmonary manifestations of rheumatoid arthritis. Clin Chest Med 1998;19, 667-685: viii.

79 Kim DS. Interstitial lung disease in rheumatoid arthritis: recent advances. Curr Opin Pulm Med 2006; 12: 346-353.

80 Schwarz MI, Lynch DA, Tuder R. Bronchiolitis obliterans: the lone manifestation of rheumatoid arthritis? Eur Respir J 1994; 7: 817-820.

81 Roschmann RA, Rothenberg RJ. Pulmonary fibrosis in rheumatoid arthritis: a review of clinical features and therapy. Semin Arthritis Rheum 1987; 16: 174-185.

82 Lee HK, Kim DS, Yoo B, et al. Histopathologic pattern and clinical features of rheumatoid arthritis-associated interstitial lung disease. Chest 2005; 127: 2019-2027.

83 Nielen MM, van Schaardenburg D, Reesink HW, et al. Specific autoantibodies precede the symptoms of rheumatoid arthritis: a study of serial measurements in blood donors. Arthritis Rheum 2004; 50: 380-386.

84 van Gaalen FA, Linn-Rasker SP, van Venrooij WJ, et al. Autoantibodies to cyclic citrullinated peptides predict progression to rheumatoid arthritis in patients with undifferentiated arthritis: a prospective cohort study. Arthritis Rheum 2004; 50: 709-715.

85 Mitsias DI, Kapsogeorgou EK, Moutsopoulos HM. Sjögren's syndrome: why autoimmune epithelitis? Oral Dis 2006; 12: 523-532.

86 Moutsopoulos HM, Chused TM, Mann DL, et al. Sjögren's syndrome (sicca syndrome): current issues. Ann Intern Med 1980; 92: 212-226.

87 Constantopoulos SH, Papadimitriou CS, Moutsopoulos HM. Respiratory manifestations in primary Sjögren's syndrome. A clinical, functional, and histologic study. Chest 1985; 88: 226-229.

88 Papiris SA, Maniati M, Constantopoulos SH, et al. Lung involvement in primary Sjögren's syndrome is mainly related to the small airway disease. Ann Rheum Dis 1999; 58: 61-64. 
89 Deheinzelin D, Capelozzi VL, Kairalla RA, et al. Interstitial lung disease in primary Sjögren's syndrome. Clinical-pathological evaluation and response to treatment. Am J Respir Crit Care Med 1996; 154: 794-799.

90 Strimlan CV, Rosenow EC III, Divertie MB, Harrison EG Jr. Pulmonary manifestations of Sjögren's syndrome. Chest 1976; 70: 354-361.

91 Parambil JG, Myers JL, Lindell RM, et al. Interstitial lung disease in primary Sjögren syndrome. Chest 2006; 130: 1489-1495.

92 Ito I, Nagai S, Kitaichi M, et al. Pulmonary manifestations of primary Sjögren's syndrome: a clinical, radiologic, and pathologic study. Am J Respir Crit Care Med 2005; 171: 632-638.

93 Bodolay E, Szekanecz Z, Devenyi K, et al. Evaluation of interstitial lung disease in mixed connective tissue disease (MCTD). Rheumatology (Oxford) 2005; 44: 656-661.

94 Maddison PJ. Mixed connective tissue disease: overlap syndromes. Baillieres Best Pract Res Clin Rheumatol 2000; 14: 111-124.

95 Prakash UB. Respiratory complications in mixed connective tissue disease. Clin Chest Med 1998;19, 733-746: ix.

96 Saito Y, Terada M, Takada T, et al. Pulmonary involvement in mixed connective tissue disease: comparison with other collagen vascular diseases using high resolution CT. J Comput Assist Tomogr 2002; 26: 349-357.

97 Alarcon-Segovia D, Villarreal M. Classification and diagnostic criteria for mixed connective tissue disease. In: Kasukawa R, Sharp GC, eds. Mixed Connective Tissue Disease and Anti-Nuclear Antibodies. Amsterdam, Excerpta Media, 1987; pp. 33-40.

98 Alarcon GS. Unclassified or undifferentiated connective tissue disease. Baillieres Best Pract Res Clin Rheumatol 2000; 14: 125-137.
99 Mosca M, Tani C, Neri C, et al. Undifferentiated connective tissue diseases (UCTD). Autoimmun Rev 2006; 6: 1-4.

100 Mosca M, Neri R, Bencivelli W, et al. Undifferentiated connective tissue disease: analysis of 83 patients with a minimum followup of 5 years. J Rheumatol 2002; 29: 2345-2349.

101 Chapman JR, Charles PJ, Venables PJ, et al. Definition and clinical relevance of antibodies to nuclear ribonucleoprotein and other nuclear antigens in patients with cryptogenic fibrosing alveolitis. Am Rev Respir Dis 1984; 130: 439-443.

102 Kinder BW, Collard HR, Koth L, et al. Idiopathic nonspecific interstitial pneumonia: lung manifestation of undifferentiated connective tissue disease? Am J Respir Crit Care Med 2007; 176: 691-697.

103 Locke GR III. The epidemiology of functional gastrointestinal disorders in North America. Gastroenterol Clin North Am 1996; 25: 1-19.

104 Locke GR III, Talley NJ, Fett SL, et al. Prevalence and clinical spectrum of gastroesophageal reflux: a population-based study in Olmsted County, Minnesota. Gastroenterology 1997; 112: 1448-1456.

105 Raghu G, Freudenberger TD, Yang S, et al. High prevalence of abnormal acid gastro-oesophageal reflux in idiopathic pulmonary fibrosis. Eur Respir J 2006; 27: 136-142.

106 Kidd K, Cusi K, Mueller R, et al. Detection and identification of significant ANAs in previously determined ANA negative samples. Clin Lab 2005; 51: 517-521.

107 Pourmand N, Blomberg S, Ronnblom L, et al. Ro 52kD autoantibodies are detected in a subset of ANA-negative sera. Scand J Rheumatol 2000; 29: 116-123.

108 Damoiseaux JG, Tervaert JW. From ANA to ENA: how to proceed? Autoimmun Rev 2006; 5: 10-17. 